\title{
Antibacterial Potency of Medicinal Plants including Artemisia annua and Oxalis corniculata against Multi-Drug Resistance E. coil
}

\author{
Hassan Golbarg $\mathbb{D}^{1}$ and Mohammad Javad Mehdipour Moghaddam $\mathbb{D}^{2}$ \\ ${ }^{1}$ Department of Biology, University Campus 2, University of Guilan, Rasht, Iran \\ ${ }^{2}$ Department of Biology, Faculty of Science, University of Guilan, 5th Kilometer of Persian Gulf Highway, Rasht, Guilan Province, \\ Iran 4199613776
}

Correspondence should be addressed to Mohammad Javad Mehdipour Moghaddam; mj_mehdipour@guilan.ac.ir

Received 20 March 2021; Revised 11 May 2021; Accepted 13 May 2021; Published 2 June 2021

Academic Editor: Stefania Cantore

Copyright (@) 2021 Hassan Golbarg and Mohammad Javad Mehdipour Moghaddam. This is an open access article distributed under the Creative Commons Attribution License, which permits unrestricted use, distribution, and reproduction in any medium, provided the original work is properly cited.

\begin{abstract}
Antibacterial activity of ethanolic and aqueous extracts of two medicinal plants including Oxalis corniculata (EtOc, AqOc) and Artemisia annua (EtAa, AqAa) as well as A. annua essential oil (EoAa) was investigated on multi-drug resistance (MDR) E. coli. Microdilution and agar well diffusion methods were used to determine the minimum inhibitory concentration (MIC), minimum bactericidal concentration $(\mathrm{MBC})$ as well as the inhibition zone. The phytconstituents of these products were analyzed using Reverse-phase High- performance liquid chromatography (RP-HPLC) and gas chromatography-mass spectrometry (GC-mass). The order of bacteriostatic and bacteriocide rate of the products can be shown as follows: EoAa $>A q O c>E t A a=A q A a>E t O c$, but the bactericidal effect of $A$. annua extracts is higher than of $O$. corniculata based on the MIC/MBC ratio and the order is as follows: $\mathrm{EoAa}>\mathrm{EtAa}=\mathrm{AqAa}>\mathrm{EtOc}>\mathrm{AqOc}$. The most potent product, i.e. EoAa with a $56.7 \%$ inhibition of all isolates, has the potential to substitute 13 used antibiotics including oxacillin, amoxicillin, ampicillin, amoxicillin-clavulanic acid, tetracycline, streptomycin, ciprofloxacin, ceftriaxone, cefazolin, cefuroxime, cefotaxime, ceftazidime and cefixime $(P<0.05)$. Different terpenoids were detected and measured in EoAa and catechin flavonoids in extracts of both plants, quercetin in extracts of $O$. corniculata but it was only possible to detect chlorogenic acid polyphenol in AqAa. Due to the antibacterial activities of the studied products, more effective than some antibiotics and their edible consumption, these products can be suggested as an alternative to some antibiotics and food preservatives to fight against MDR E. coli.
\end{abstract}

\section{Introduction}

The emergence of resistance among Enterobacteriaceae as the most common human bacterial pathogen to a wide range of antibiotics, a great deal of burden is being forced on patients and healthcare systems [1]. The Enterobacteriaceae of pathogens accounts for $80 \%$ of Gram-negative bacterial isolates that cause a variety of human diseases, including urinary tract infections (UTIs). Escherichia coli is the most common cause of UTI, accounting for $85 \%$ and $50 \%$ of community-acquired and hospital-acquired UTIs, respectively [2]. E. coli bloodstream infection sources (BSIs) were found to have a urinary source in $34 \%$ of cases [3].
Also, E. coli is the most prevalent microorganism responsible for health-related infections in the United States, according to the National Healthcare Safety (NHSN) Network [1]. Antibiotic resistance is caused by misuse, overuse and under-use of antibiotics by humans and is thus hazardous and threatening to public health [4].

Antibiotic resistance has been reported around the world in E. coli, with more than $95 \%$ of cases treated with serious symptoms prior to any culture detection. The emergence of MDR E. coli, particularly in infections such as UTIs associated with treatment defects occurs after the antibiotics prescription without any culture and the widespread use of antibiotics in clinics $[5,6]$. The multi-drug resistance (MDR) 
bacteria survive exposure to antibiotics, so common medication become ineffective and infection persist, increasing the spread of infection [7]. Therefore, MDR bacteria are considered as a challenge in medicine.

Studies on chemical compounds of natural origin, in particular plants, have been ongoing for a long time, so that certain plants extracts or other herbal products can be used as an alternative source for the fight against antibiotic-resistant bacteria.

Of the approximately 500,000 known plant species, only $1-10 \%$ is used as human and animal food. Herbs have long been used as drugs to combat infections. Since ancient times, plants have been used as a remedy against infection, and even today, plant products are used almost all over the world, so that about $50 \%$ of pharmaceutical products are of plant origin in the United States $[4,8]$.

The plant products are complex set of primary and secondary metabolites, and their biological and pharmacological function may be due to synergies between different chemical components. The chemical components and levels of active compounds in these products are very diverse due to the plant interaction with the environment and other organisms. Since the manufacturing process of herbal medicinal products is very complex, it is preferable to use pure chemical compounds of plant origin due to easy of prescription, study the mechanism of pharmacological action and monitoring their side effects $[9,10]$.

Different plant secondary metabolites such as flavonoids, terpenes, phenolic acids, alkaloids, carotenoids, tannins, coumarins as well as some primary metabolites, such as peptides, amino acids, and organic acids show antimicrobial activity. Flavonoids have more benefits among the secondary metabolites mentioned and are found in different vegetables, fruits and plants and exhibit various activities, including antioxidant, immunomodulatory, anti-inflammatory, anti-cancer, neuroprotective and antidiabetic effects [11-13]. Plants containing polyphenols, due to their antimicrobial and antioxidant activity, are most of the medicinal plants studied $[14,15]$.

In this study, the antibacterial effects of two plant species including Artemisia annua and Oxalis corniculata were investigated. The genus Artemisia (Family Asteraceae) belongs to a valuable aromatic and medicinal plant group consisting of approximately 300 species found in the northern hemisphere. In Iran, there are about 34 native Artemisia spp. [16, 17]. A. annua called Qinghaosu, Sweet Sagewort, Sweet Annie, Sweet Wormwood, Annual Wormwood, is an annual plant which is widely distributed in Europe, Asia and North America, originating in China [18-20]. This plant has been used to treat malaria since ancient times [19]. The anti-malarial property of this plant is due to the presence of artemisinin sesquiterpene, and this plant has the potential for commercial development because of this compound [21, 22]. Moreover, this plant has antimicrobial, anticancer, anti-inflammatory, antipyretic, antiparasitic properties due to the existence of secondary metabolites such as flavonoids, monoterpenoids, sesquiterpenoids, coumarins, and aliphatic and lipid compounds [23, 24].

O. corniculata is a member of the Oxalidaceae family, also known as creeping wood sorrel or procumbent yellow sorrel, or the sleeping beauty [25]. Of the Oxalidaceae family, there is only the Oxalis genus in Iran [26]. There are about 900 species of the Oxalis genus that are mainly distributes in central South America's temperate and subtropical regions, including some other parts of the world common in Africa, Philippines, China, warmer parts of India and Pakistan [27]. Only two species have been reported from Iran, including O. corniculata and O. articulate [26].

O. corniculata is a well-known herb that has an acidic taste because of the high oxalate level of its stems and leaves [28]. It is usually distributed in Africa and Asia's subtropical regions [25]. Phytochemical analysis of this plant showed the presence of a mixture of different fatty acids and revealed the presence of flavonoids, phenolic compounds, phytosterols, essential oils, glycosides, proteins and amino acids in its ethanolic and methanolic extracts. Flavones, calcium oxalate, citric acid and tartaric acid are found in its leaves [29].

The aim of this study was to investigate the antimicrobial potential of ethanolic and aqueous extracts of $A$. annua and $O$. corniculata as well as $O$. corniculata essential oil on MDR E. coli isolates and also to identify some antimicrobial compounds in their products.

\section{Material and Methods}

2.1. Bacterial Isolation. This study was conducted on 138 urine cultures were obtained from patients, both women and men, suspected to have an UTI. The freshly voided midstream urine samples were transferred to the laboratory to avoid contamination as quickly as possible on deliver. Urine specimen was inoculated on the Cystine Lactose ElectrolyteDeficient (CLED) agar using standard culture methods. The CLED plates were incubated for $24 \mathrm{~h}$ at $37^{\circ} \mathrm{C}$. Urine samples that contain $\geq 10^{5}$ colony-forming per milli-liter $(\mathrm{CFU} / \mathrm{ml})$ are considered positive [30,31]. After isolation of bacteria using culture, Gram staining and biochemical differential tests were used to identify E. coli [32]. For further analysis, the isolates were stored at $-70^{\circ} \mathrm{C}$ in a Tryptic Soy Broth containing 15\% glycerol.

2.2. Antimicrobial Susceptibility. Antimicrobial susceptibility testing was conducted by the Kirby-Bauer disc diffusion system on Mueller-Hinton agar. This test was carried out using the following antibiotic disks (oxoid) against $E$ coli isolates: oxacillin (OXA) $(5 \mu \mathrm{g})$, ampicillin (AMP) $(10 \mu \mathrm{g})$, piperacillin (PIP) $(100 \mu \mathrm{g})$, amoxicillin $(\mathrm{AMX})(25 \mu \mathrm{g})$, amoxicillinclavulanic acid (AMC) $(20 / 10 \mu \mathrm{g})$, fosfomycin (FOF) $(200 \mu \mathrm{g})$, tetracycline (TE) $(30 \mu \mathrm{g})$, ciprofloxacin (CIP) $(5 \mu \mathrm{g})$, streptomycin (STR) $(10 \mu \mathrm{g})$, chloramphenicol (CHL) $(30 \mu \mathrm{g})$, cephalothin $(\mathrm{CEF})(30 \mu \mathrm{g})$, cefazolin $(\mathrm{CFZ})(30 \mu \mathrm{g})$, cefixime (CFM) $(5 \mu \mathrm{g})$, cefuroxime $(\mathrm{CXM})(30 \mu \mathrm{g})$, cefotaxime (CTX) $(30 \mu \mathrm{g})$, ceftriaxone $(\mathrm{CRO})(30 \mu \mathrm{g})$, ceftazidime $(\mathrm{CAZ})(30 \mu \mathrm{g})$, meropenem $(\mathrm{MEM})(10 \mu \mathrm{g})$, imipenem (IMP) $(10 \mu \mathrm{g})$ and cefepime $(\mathrm{FEP})(30 \mu \mathrm{g})[33,34]$.

2.3. Preparation of Extracts. The leaves of two plants, including A. annua (ASA52185) and O. corniculata (OXO28252), which were collected from the Lahijan and Rasht regions in Gilan Province in northern Iran, were used to extract and 
study the antimicrobial activities. The identification and confirmation of species was performed by Dr. Davod Bakhsi and then voucher specimens deposited in the botanical herbarium at the Faculty of Agricultural Sciences, University of Guilan, Iran (with identification code, as indicated in parentheses above). The leaf samples of the two plants were cleaned, dried in an oven at $45^{\circ} \mathrm{C}$, ground into fine powder and weighed exactly, and then subjected to extraction with ethanol $70 \%$ and water solvents at room temperature using Soxhlet system [35].

In aqueous extraction, $1 \mathrm{~g}$ of the leaf powder is soaked in $10 \mathrm{ml}$ of distilled water in conical flask and put at $90^{\circ} \mathrm{C}$ for $60 \mathrm{~min}$. Finally, the resulting suspension is incubated as overnight on the shaker incubator at $37^{\circ} \mathrm{C}, 150 \mathrm{rpm}$. Aqueous extract obtained was separated from solid residues by filtration using Whatman No. 1 filter paper. For ethanolic extraction, $1 \mathrm{~g}$ of each grinned plant material was extracted by $15 \mathrm{ml}$ ethanol $70 \%$ for $12 \mathrm{~h}$ with continuous vigorous shaking at $30 \mathrm{~min}$ intervals. Then, the mixtures were filtered through Whatman No. 1 filter paper. The filtrate was collected and condensed by the rotary evaporator at $80^{\circ} \mathrm{C}$ for ethanol removal [35].

The oil extraction was performed according to the European Pharmacopoeia. A $300 \mathrm{~g}$ of the leaf powder of O. corniculata was mixed with $1000 \mathrm{ml}$ of distilled water in $1000 \mathrm{ml}$ distillation flask and hydrodistilled using an apparatus of Clevenger type for $3 \mathrm{~h}$. The distillation flask was put in the hot plate and, with the addition of boiling chips, allowed the sample to boil until the distillation was accomplished. The extract (distillate) was collected in receiver apparatus. The extracted fractions of leaves displayed two separate layers including the lower aqueous layer and an upper oily layer. The oil was separated from the aqueous layer using a separatory funnel by extracting it twice with chloroform. After filtration of extracted oil, the chloroform was removed using rotary evaporator at $35^{\circ} \mathrm{C}$. The obtained oil was dried over anhydrous sodium sulphate, filtered, concentrated under vacuum and then stored at $4^{\circ} \mathrm{C}$ in refrigerator until used for antimicrobial analysis [36].

2.4. Antimicrobial Activity. To evaluate the antibacterial potency of extracts and essential oil, the agar well diffusion and broth micro-dilution susceptibility methods were used. Due to the long name of each plant product, the abbreviations of each of them are as follows: essential oil, ethanolic and aqueous extracts of A. annua = EoAa, EtAa and AqAa; ethanolic and aqueous extracts of $O$. corniculat $a=$ EtOc and AqOc. To perform the diffusion agar well diffusion test, plates containing Muller Hinton Agar (MHA) medium are prepared and then $10 \mathrm{~mm}$ diameter wells are made on the medium using a cork borer. After preparation of the MAH medium, a suspension with a $0.5 \mathrm{McF}$ arland $\left(1.5 \times 10^{8} \mathrm{CFU} / \mathrm{ml}\right)$ density is prepared from the test isolate and spread on the surface of the medium using a swab moistened with bacterial suspension. About $50 \mu \mathrm{l}$ of each plant product $\left(10^{-1}\right.$ to $\left.10^{-7}\right)$ is inoculated into the well. All plates are incubated for $24 \mathrm{~h}$ at $37^{\circ} \mathrm{C}$ and then the diameters of the inhibition zones were measured [37].

In the broth micro-dilution susceptibility method, 96well microplate was used to determine minimum inhibitory concentration (MIC) and the minimum bactericidal concentration (MBC) of plant products. A serial dilution of $10^{-1}$ to $10^{-7}$ was prepared from each product and $50 \mu \mathrm{l}$ of product, $50 \mu \mathrm{l}$ of MHA medium and $50 \mu \mathrm{l}$ of $0.5 \mathrm{McFarland}$ suspension from the test isolate were added within each well. MIC and $\mathrm{MBC}$ of each product were determined after incubation for $24 \mathrm{~h}$ at $37^{\circ} \mathrm{C}$. To determine $\mathrm{MBC}$, the content of the well without growth was inoculated on the MHA plate and if the isolate did not grow on the plate, that concentration was considered as MBC [38]. The amount of product that inhibits or kills bacteria can be determined using MIC and $\mathrm{MBC}$ quantities. Antimicrobials are usually considered as bactericidal, if the $\mathrm{MBC} / \mathrm{MIC}$ ratio is not more than 4 [39].

2.5. HPLC Analysis. The extracts were analyzed using Reversed- phase High- performance liquid chromatography (RP-HPLC) to exhibit and quantify of antimicrobial compounds including catechin, quercetin and chlorogenic acid. A $1 \mathrm{~g}$ of grind leaves was extracted with $6 \mathrm{ml}$ of methanol and acetic acid extraction solvent $(85: 15, \mathrm{v} / \mathrm{v})$. The obtained extract was filtered, concentrated and dried using a rotary evaporator. The dried extract was being dissolved in the mobile phase. Fifty $\mu$ l of prepared extract was injected in HPLC (Waters, 1525, Milford, USA) equipped with a UVVisible detector (Waters Dual $\lambda$ Absorbance 2487), C18 column: Waters Symmetry C18 $5 \mu \mathrm{m} 5 \times 150 \mathrm{~mm}$ (Waters, Dublin, Ireland), at 280 and $320 \mathrm{~nm}$. The compounds were detected by comparing retention times and UV-DAD (280 and $320 \mathrm{~nm}$ ) spectra with those for standard solutions. In order to measure phenolic acid in extracts, the integrated peak area was calculated, and the contents were estimated using the calibration curve by plotting the peak area against the concentration of the corresponding standard sample [40].

2.6. GC-MS Analysis. The A. annua essential oil components was quantified by Gas chromatography-mass spectrometry (GC-MS), an Agilent 6850 gas chromatograph coupled to an Agilent 7890A mass spectrometer. The components were separated on a HP-5MS UI capillary column $(30 \mathrm{~m}, 0.25 \mathrm{~mm}$, $0.25 \mu \mathrm{m})$ including $5 \%$ phenyl polysiloxane as stationary phase. The oven temperature program was started at $50^{\circ} \mathrm{C}$, retained for $3 \mathrm{~min}$, then increased from $8^{\circ} \mathrm{C} \mathrm{min}^{-1}$ to $250^{\circ} \mathrm{C}$, and retained for $2 \mathrm{~min}$. The Injector, interface and ion source temperatures were retained at 250,250 and $220^{\circ} \mathrm{C}$, respectively. The split injection $(1 \mu \mathrm{l})$ was carried out with a $1: 50$ split ratio and helium was applied as carrier gas with flowrate of $1 \mathrm{ml} / \mathrm{min}$. The spectrometers operated in the electron ionization (EI) mode and the scan mass range, the ionization energy and the scan rate were $3-500 \mathrm{~m} / \mathrm{z}, 70 \mathrm{eV}$ and $0.2 \mathrm{~s}$ per scan, respectively. The components of the essential oil were identified based on a comparison of their mass spectra with those of the NIST mass library [41].

2.7. Statistical Analysis. All measurements have been replicated three times, and data was reported as mean \pm SD. The results were statistically evaluated using a one-way variance analysis (ANOVA) and the variations between the means were calculated using the multiple range tests of Duncan at $P \leq 0.01$. 


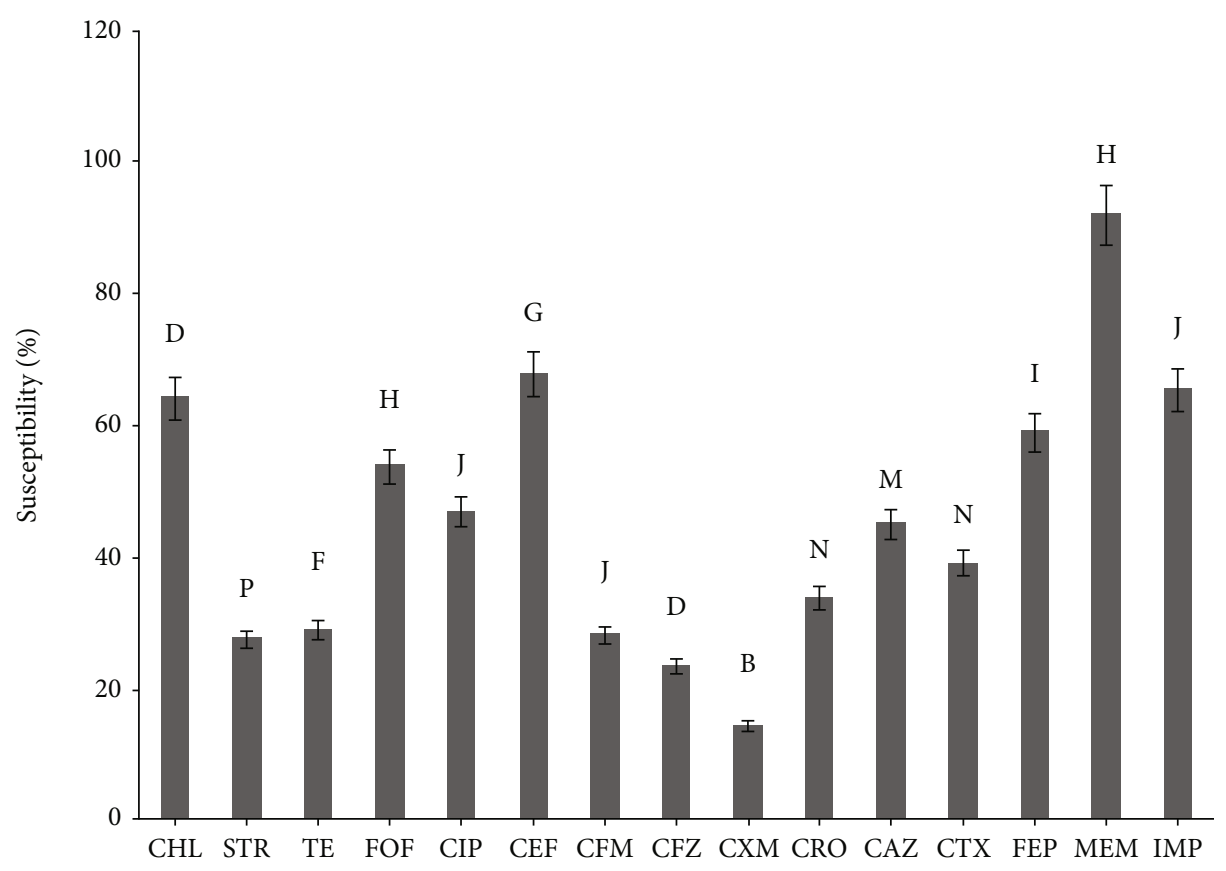

Figure 1: Susceptibility patterns of MDR E. coli isolates to different antibiotics. Values marked by different letters (a, b) are significantly different $(P<0.05)$.

\section{Results}

3.1. E. Coli Isolates. E. coli were identified in 91 samples out of the 138 urine samples included in this study. Identification of E. coli based on observation of Gram-negative coccobacilli, $\beta$-hemolysis on blood agar, pink colonies on McConkey, greenish metallic sheen on EMB, indole production, positive MR reaction, nitrate reduction, enzymes production including catalase, Ornithine decarboxylase, $\beta$-glucosidase, $\mathrm{CO}_{2}$ production as well as glucose, lactose, manntiol and maltose fermentation. All E. coli isolates differ from each other, because they are distinct in their susceptibility pattern to the antibiotics used. The susceptibility pattern of the isolates to antibiotics used is shown in Figure 1. Since each isolate was resistant to at least three antibiotics, all isolates are referred to as MDR. Among the antibiotics used, meropenem and penicillins with the exception of piperacillin, were the most potent and weakest antibiotics against $E$. coli isolates, respectively. After meropenem $(91.90 \% \pm 1.89)$, piperacillin $(78.94 \% \pm$ 3.41) was the most effective antibiotic, followed by the three antibiotics including imipenem $(65.34 \% \pm 1.79)$, cefepime $(67.77 \% \pm 2.20)$, and chloramphenicol $(64.07 \% \pm 3.15)$.

3.2. Antimicrobial Potency of Herbal Products. Preliminary antimicrobial screening test using agar well diffusion method was performed on 91 MDR E. coli isolates. Although a concentration range of $10^{-7}-11.11 \mathrm{mg} / \mathrm{ml}$ was used to investigate the antimicrobial activity of the products, with the exception of one case of $O$. corniculata product and three cases of $A$. annua products, no activity of any of the products at concentrations below $0.0001 \mathrm{mg} / \mathrm{ml}$ was observed.

Some products had no effect on several isolates at the concentrations used. Some of them have an antimicrobial activity on one isolate, while the same isolate was not susceptible to another product from the same plant. According to the antimicrobial assay methods used, some products had a similar effect on different isolates and vice versa. Based on the results of agar well diffusion test shown in Table 1, A. annua extracts had a greater effect on more isolates than $O$. corniculata extracts. According to the data presented in Table 1, the most potent plant product used, EoAa, was capable of creating an inhibition zone (i.d) with a diameter of $20 \pm 1.45 \mathrm{~mm}$ in $11.11 \mathrm{mg} / \mathrm{ml}$ concentration, although some extracts were able to make an i.d almost similar to EoAa. In the current study, the diameter range of i.d was from $4 \pm$ 0.33 to $20 \pm 1.45 \mathrm{~mm}$. The mean i.d was higher in antibioticsusceptible isolates than that of the studied herbal products.

To accurately quantify the amounts of plant products as MIC and MBC that inhibit and kill isolates, the microdilution method was applied and their results were shown in Table 2 and Figure 2.

The AqAa and EtOc extracts had no inhibitory effect on any of the isolates at the lowest concentrations used, and the antimicrobial effects of EoAa and AqOc extract were similar. In general, EoAa and EtOc extract were the most potent and the weakest bacteriostatic products, respectively. The inhibitory activity was similar for both $A$. annua extracts, but the AqOc extract showed more bacteriostatic activity than the ethanolic type. The order of inhibition by the products can be shown as follows: EoAa $>\mathrm{AqO} c>$ EtAa $=\mathrm{AqAa}>\mathrm{E}-$ tOc. The product's bactericidal effect can be expressed both in terms of the MIC/MBC ratio $(<4)$ and based on MBC alone. According to the latter case, the same inhibitory order is established for bactericidal activity, but the bactericidal effect of $A$. annua extracts is higher than that of O. corniculata extracts based on the MIC/MBC ratio (Table 3 ). 
TABle 1: Antimicrobial potency of the herbal products against MDR E. coli isolates assayed by agar well diffusion method.

\begin{tabular}{|c|c|c|c|c|c|}
\hline Isolates & EoAa & EtAa & $\begin{array}{c}\text { Mean } \pm \text { SD }(\mathrm{mm}) \\
\mathrm{AqAa}\end{array}$ & EtOc & $\mathrm{AqOc}$ \\
\hline I1 & $8 \pm 0.21$ & - & - & - & - \\
\hline $\mathrm{I} 2$ & - & - & - & - & - \\
\hline I3 & $10 \pm 0.12$ & $7 \pm 0.44$ & - & $6 \pm 0.24$ & $11 \pm 0.76$ \\
\hline $\mathrm{I} 4$ & $9 \pm 0.34$ & $14 \pm 1.60$ & $8 \pm 0.56$ & $5 \pm 0.33$ & - \\
\hline I5 & - & - & - & - & - \\
\hline I6 & - & - & - & - & - \\
\hline I7 & $13 \pm 0.46$ & - & - & - & - \\
\hline I8 & - & - & - & $10 \pm 0.46$ & $14 \pm 1.33$ \\
\hline I9 & $11 \pm 0.48$ & - & - & - & - \\
\hline $\mathrm{I} 10$ & $16 \pm 0.37$ & $12 \pm 1.46$ & $10 \pm 0.76$ & - & $6 \pm 0.76$ \\
\hline I11 & - & - & - & - & - \\
\hline $\mathrm{I} 12$ & $7 \pm 0.22$ & $9 \pm 0.33$ & - & - & - \\
\hline $\mathrm{I} 13$ & $14 \pm 0.46$ & $11 \pm 0.76$ & $6 \pm 0.48$ & $11 \pm 1.86$ & $10 \pm 0.76$ \\
\hline I14 & - & - & $8 \pm 0.27$ & $10 \pm 1.33$ & $13 \pm 0.87$ \\
\hline $\mathrm{I} 15$ & - & - & - & - & - \\
\hline I16 & - & - & - & - & $6 \pm 0.56$ \\
\hline I17 & $6 \pm 0.12$ & $11 \pm 0.76$ & - & $5 \pm 0.56$ & $9 \pm 1.76$ \\
\hline I18 & - & - & - & - & - \\
\hline I19 & $7 \pm 0.46$ & $5 \pm 0.22$ & $7 \pm 0.48$ & - & $6 \pm 1.15$ \\
\hline $\mathrm{I} 20$ & $17 \pm 2.48$ & $12 \pm 0.26$ & $11 \pm 0.35$ & - & - \\
\hline $\mathrm{I} 21$ & - & - & - & - & $6 \pm 0.76$ \\
\hline $\mathrm{I} 22$ & - & - & $7 \pm 0.33$ & - & - \\
\hline $\mathrm{I} 23$ & $5 \pm 0.27$ & - & - & - & - \\
\hline $\mathrm{I} 24$ & $15 \pm 0.64$ & $6 \pm 0.33$ & $11 \pm 0.64$ & - & - \\
\hline $\mathrm{I} 25$ & $6 \pm 0.33$ & $5 \pm 0.27$ & $6 \pm 0.45$ & - & $7 \pm 1.33$ \\
\hline I26 & $7 \pm 0.56$ & - & - & $4 \pm 0.33$ & $4 \pm 0.87$ \\
\hline I 27 & - & - & - & - & - \\
\hline $\mathrm{I} 28$ & $8 \pm 0.36$ & $6 \pm 0.55$ & $7 \pm 0.12$ & $5 \pm 0.46$ & $9 \pm 1.66$ \\
\hline I29 & $15 \pm 1.76$ & $10 \pm 0.44$ & $11 \pm 0.55$ & - & - \\
\hline $\mathrm{I} 30$ & $4 \pm 0.36$ & $4 \pm 0.22$ & & $11 \pm 1.54$ & $13 \pm 2.66$ \\
\hline $\mathrm{I} 31$ & - & - & - & - & - \\
\hline $\mathrm{I} 32$ & $15 \pm 0.46$ & $20 \pm 2.66$ & $10 \pm 0.74$ & $14 \pm 1.64$ & $17 \pm 2.65$ \\
\hline I33 & $15 \pm 0.28$ & $13 \pm 0.62$ & $6 \pm 0.33$ & - & - \\
\hline I34 & - & - & - & $8 \pm 0.67$ & $12 \pm 1.36$ \\
\hline I35 & $6 \pm 0.27$ & - & - & - & - \\
\hline I36 & $7 \pm 0.44$ & $5 \pm 0.21$ & $7 \pm 0.86$ & - & - \\
\hline I37 & - & - & - & $9 \pm 0.66$ & $11 \pm 1.66$ \\
\hline I38 & - & - & - & - & - \\
\hline I39 & $8 \pm 0.44$ & - & - & $8 \pm 0.64$ & $11 \pm 1.34$ \\
\hline $\mathrm{I} 40$ & $6 \pm 0.32$ & - & - & - & - \\
\hline I41 & - & - & - & $10 \pm 1.66$ & $13 \pm 2.64$ \\
\hline I442 & $11 \pm 0.27$ & $7 \pm 0.56$ & $5 \pm 0.24$ & - & - \\
\hline I43 & - & - & - & - & - \\
\hline I44 & $6 \pm 0.33$ & - & - & $9 \pm 0.76$ & $9 \pm 1.64$ \\
\hline I45 & - & - & - & - & - \\
\hline I46 & $7 \pm 0.44$ & $5 \pm 0.24$ & $5 \pm 0.78$ & - & $6 \pm 0.76$ \\
\hline $\mathrm{I} 47$ & $17 \pm 1.22$ & $12 \pm 0.76$ & $7 \pm 0.54$ & - & - \\
\hline I 48 & $7 \pm 0.46$ & $6 \pm 0.33$ & $8 \pm 055$ & $6 \pm 0.54$ & $8 \pm 1.33$ \\
\hline
\end{tabular}


TABle 1: Continued.

\begin{tabular}{|c|c|c|c|c|c|}
\hline Isolates & EoAa & EtAa & $\begin{array}{c}\text { Mean } \pm \text { SD }(\mathrm{mm}) \\
\mathrm{AqAa}\end{array}$ & EtOc & $\mathrm{AqOc}$ \\
\hline I49 & - & - & - & - & - \\
\hline $\mathrm{I} 50$ & $14 \pm 0.46$ & $14 \pm 2.12$ & $10 \pm 0.62$ & - & - \\
\hline I51 & $6 \pm 0.46$ & - & - & $9 \pm 1.66$ & $8 \pm 0.64$ \\
\hline $\mathrm{I} 52$ & - & - & - & - & - \\
\hline I53 & $7 \pm 0.84$ & $6 \pm 0.33$ & - & $8 \pm 1.64$ & $11 \pm 2.33$ \\
\hline I54 & $5 \pm 0.24$ & $7 \pm 0.43$ & $5 \pm 0.36$ & - & $6 \pm 0.56$ \\
\hline I55 & $15 \pm 1.54$ & $4 \pm 0.16$ & $11 \pm 0.56$ & $5 \pm 0.33$ & $8 \pm 0.64$ \\
\hline I56 & - & - & - & - & - \\
\hline I57 & - & - & - & - & - \\
\hline I58 & $6 \pm 0.64$ & - & - & - & - \\
\hline I59 & $16 \pm 1.42$ & $10 \pm 0.22$ & $12 \pm 1.89$ & $7 \pm 1.64$ & $10 \pm 2.64$ \\
\hline I60 & $14 \pm 0.76$ & $5 \pm 0.65$ & $10 \pm 1.20 \mathrm{~b}$ & - & - \\
\hline I61 & $10 \pm 0.97$ & - & $6 \pm 0.76$ & $9 \pm 1.64$ & $11 \pm 1.66$ \\
\hline I62 & - & - & - & - & - \\
\hline I63 & - & - & - & - & - \\
\hline I64 & $14 \pm 1.60$ & $10 \pm 0.86$ & $10 \pm 1.40$ & - & - \\
\hline I65 & - & - & - & $9 \pm 1.76$ & $9 \pm 1.33$ \\
\hline I66 & - & - & - & - & - \\
\hline I67 & $19 \pm 2.60$ & $5 \pm 0.62$ & $13 \pm 1.60$ & - & $6 \pm 0.64$ \\
\hline $\mathrm{I} 68$ & - & - & - & - & - \\
\hline I69 & $15 \pm 2.30$ & $7 \pm 0.62$ & $10 \pm 1.60$ & - & - \\
\hline I70 & - & - & - & - & - \\
\hline I71 & - & - & - & - & - \\
\hline $\mathrm{I} 72$ & $13 \pm 1.85$ & $6 \pm 0.33$ & $11 \pm 1.62$ & $9 \pm 0.87$ & $12 \pm 1.87$ \\
\hline I73 & - & - & - & $8 \pm 1.64$ & $7 \pm 0.46$ \\
\hline I74 & - & - & - & - & - \\
\hline $\mathrm{I} 75$ & - & - & - & - & - \\
\hline I76 & - & - & - & $11 \pm 0.56$ & $9 \pm 1.64$ \\
\hline I77 & $14 \pm 2.60$ & - & $10 \pm 1.80$ & - & - \\
\hline I78 & - & - & - & $9 \pm 1.76$ & $11 \pm 2.64$ \\
\hline I79 & - & - & - & $5 \pm 0.12$ & $8 \pm 1.33$ \\
\hline I80 & $9 \pm 0.26$ & $4 \pm 0.26$ & $10 \pm 0.64$ & - & - \\
\hline I81 & $10 \pm 2.60$ & $5 \pm 0.86$ & $10 \pm 0.86$ & $7 \pm 1.66$ & $9 \pm 2.66$ \\
\hline I82 & - & - & - & - & - \\
\hline I83 & - & - & - & $8 \pm 0.64$ & $7 \pm 0.46$ \\
\hline I84 & - & - & - & - & - \\
\hline I85 & $7 \pm 0.22$ & - & $5 \pm 0.86$ & - & - \\
\hline I86 & - & - & - & $11 \pm 1.64$ & $13 \pm 2.76$ \\
\hline I87 & - & - & - & - & - \\
\hline I88 & $15 \pm 1.45$ & $10 \pm 1.24$ & $14 \pm 2.64$ & - & - \\
\hline I89 & $6 \pm 0.49$ & $6 \pm 1.33$ & $8 \pm 1.60$ & - & - \\
\hline I90 & - & - & - & - & - \\
\hline I91 & $20 \pm 2.45$ & $11 \pm 1.36$ & $14 \pm 2.45$ & $5 \pm 0.56$ & $4 \pm 0.24$ \\
\hline
\end{tabular}

All data presented was at a concentration of $11.11 \mathrm{mg} / \mathrm{ml}$ of the product. EoAa, EtAa and AqAa: essential oil, ethanolic and aqueous extracts of A. annua; EtOc and AqOc: ethanolic and aqueous extracts of O. corniculata.

Therefore, in comparing the two methods, the findings can vary, although the activity of EoAa in both methods is higher than that of all extracts from both plants.
The MIC and MBC values obtained from all products ranged from $10^{-4}$ to $11.11 \mathrm{mg} / \mathrm{ml}$, and in MICs less than $10^{-4} \mathrm{mg} / \mathrm{ml}$, none of the products had any activity on any 


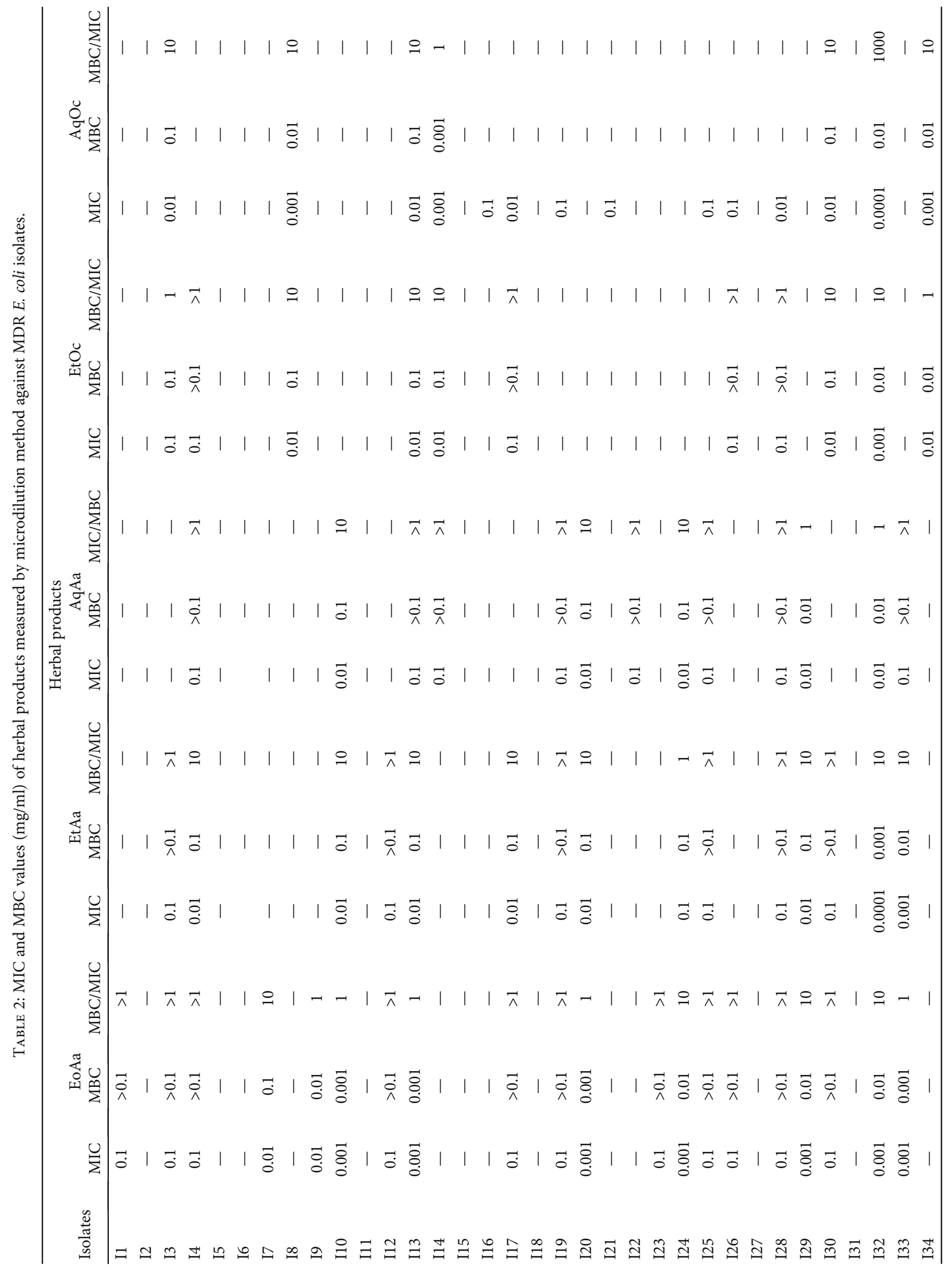




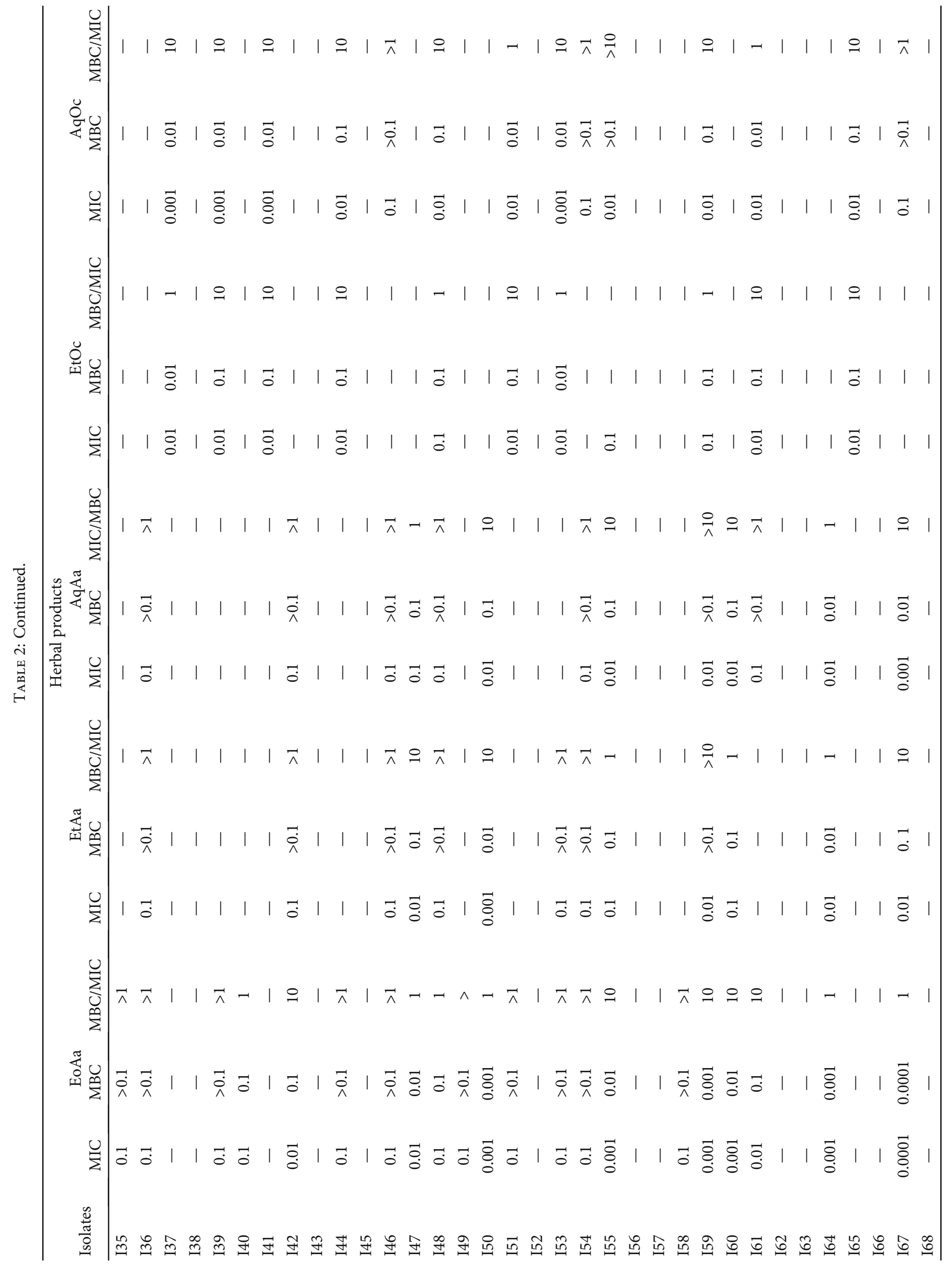




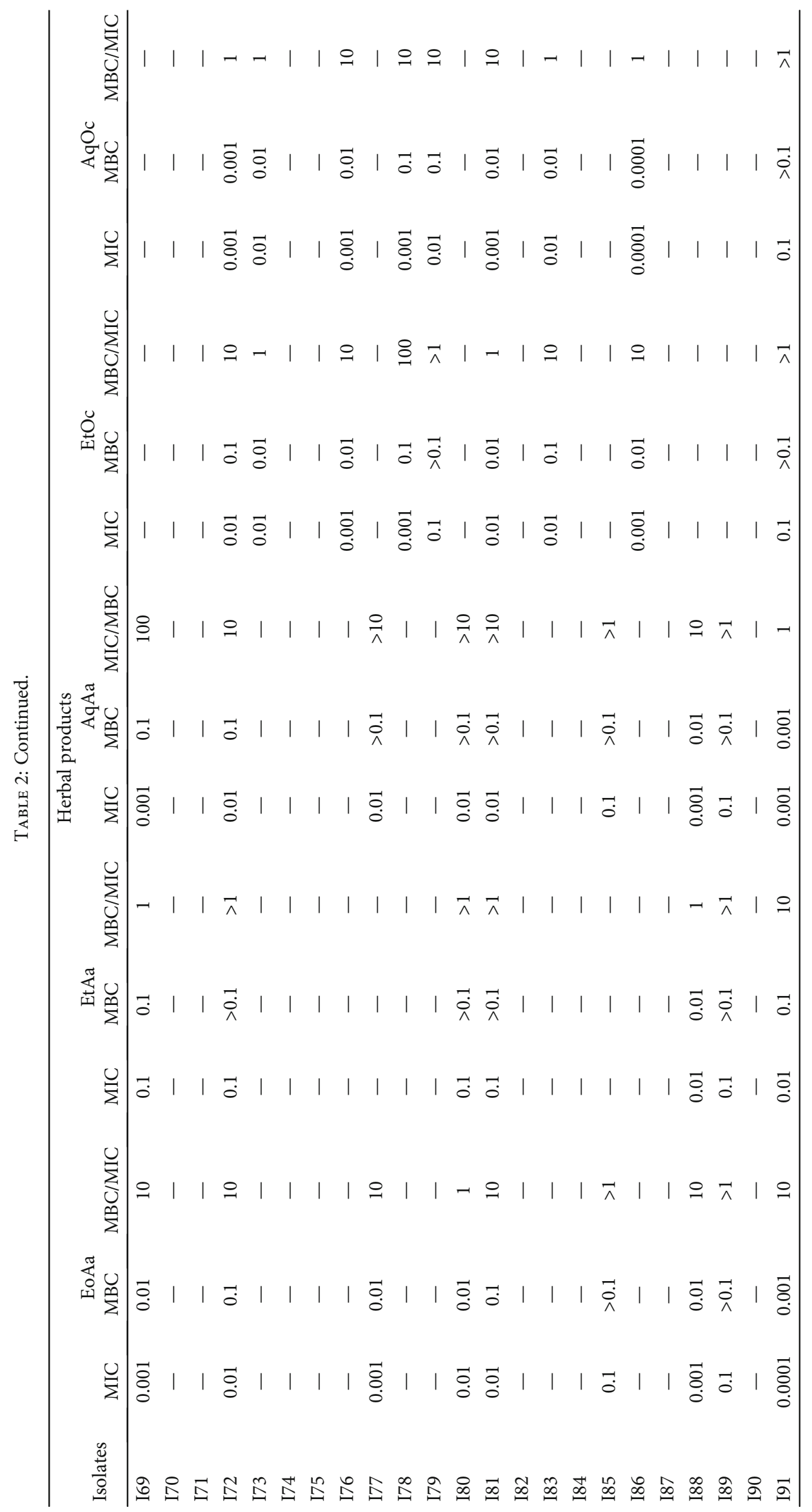




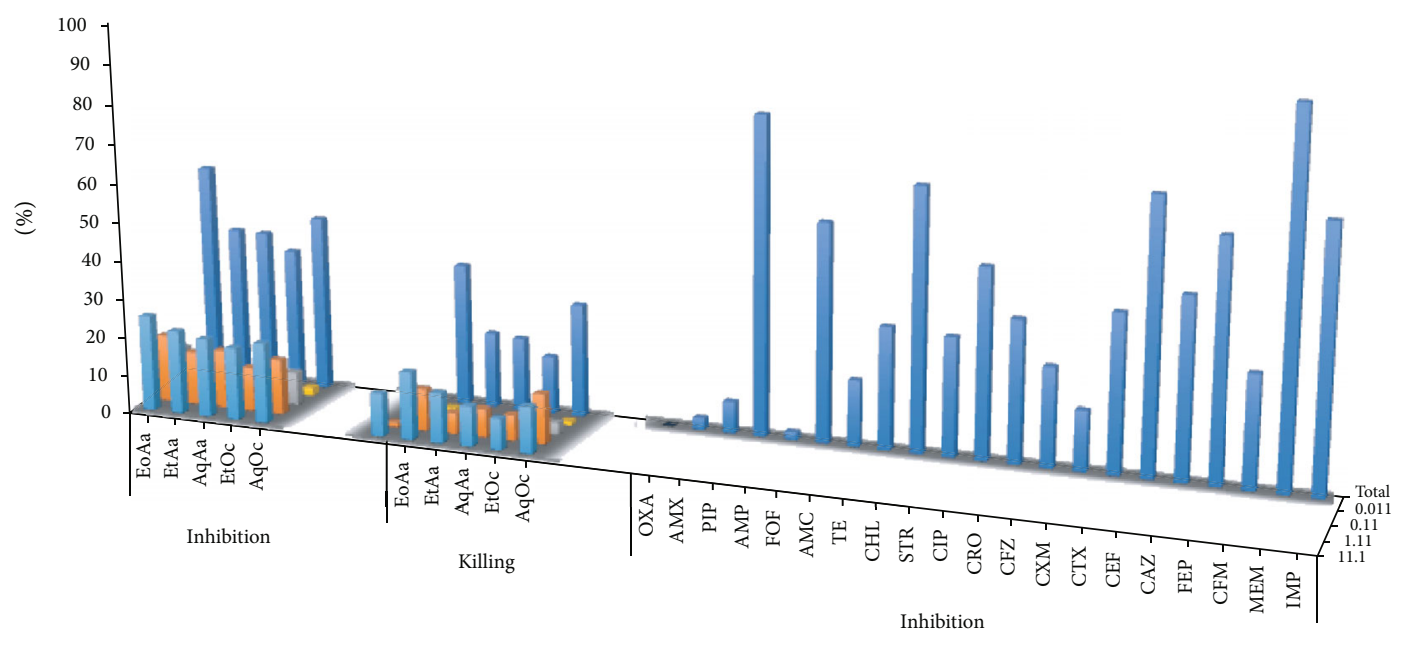

\begin{tabular}{|c|c|c|c|c|c|c|c|c|c|c|c|}
\hline \multicolumn{7}{|c|}{ Inhibition } & \multicolumn{4}{|c|}{ Killing } & Inhibition \\
\hline \multicolumn{7}{|c|}{ EoAa EtAa AqAa EtOcAqOc } & \multicolumn{4}{|c|}{ EoAa EtAa AqAa EtOc AqOc } & OXA AMX PIP AMPFOFAMC TE CHL STR CIP CRO CFZ CXMCTXCEF CAZ FEP CFM MEM IMP \\
\hline . & 11.1 & 24.8 & 21.6 & 20.3 & 18.8 & & 11.117 .5 & 12.9 & 10.4 & $48.2 \quad 12$ & \\
\hline . & 1.11 & 17.5 & 13.8 & 15.1 & & & 1.1110 .8 & 5.4 & 7.3 & 6.612 .9 & \\
\hline - & 0.11 & 12.2 & 4.2 & 5.2 & 6.3 & 8.6 & 0.117 .5 & 1.1 & 1.1 & 3.2 & \\
\hline = & 0.011 & 2.2 & 1.1 & 0 & 0 & 2.2 & $\begin{array}{ll}0.01 & 1.1\end{array}$ & 0 & 0 & 1.1 & \\
\hline
\end{tabular}

FIGURE 2: Comparison of the bacteriostatic and bacteriocide potency (\%) of different concentrations $(0.011,0.11,1.11 \mathrm{and} 11.11 \mathrm{mg} / \mathrm{ml})$ of two plant products with antibiotics against on MDR E. coil. EoAa, EtAa and AqAa = essential oil, ethanolic and aqueous extracts of $A$. annua; EtOc and $\mathrm{AqOc}=$ ethanolic and aqueous extracts of $O$. corniculata.

TABLE 3: MBC/MIC ratio equal to $0,1,>1,10,>10,100$ and 1000 of various extracts on MDR E. coli isolates. If the bactericidal effect is expressed in terms of $\mathrm{MBC} / \mathrm{MIC}$ ratio $(<4)$, the bacterocide activity of $A$. annua products is weaker than that of $O$. corniculata.

\begin{tabular}{lccccc}
\hline & \multicolumn{5}{c}{ Herbal products } \\
MBC/MIC ratio & EoAa & EtAa & AqAa & EtOc & AqOc \\
\hline 0 & 41 & 55 & 56 & 61 & 41 \\
1 & 12 & 6 & 5 & 8 & 0 \\
$>1$ & 23 & 16 & 16 & 6 & 4 \\
10 & 15 & 13 & 9 & 15 & 17 \\
$>10$ & 0 & 1 & 4 & 0 & 1 \\
100 & 0 & 0 & 1 & 1 & 0 \\
1000 & 0 & 0 & 0 & 0 & 1 \\
\hline
\end{tabular}

of the isolates. In some cases, the MIC and MBC values for the products were the same, but in most cases the MBC values were higher than the MIC values. In A. annua products, there were three cases of $\mathrm{MIC}=10^{-4} \mathrm{mg} / \mathrm{ml}$, including one case of EtAa extract and two cases of EoAa and also one case of $\mathrm{MBC}=10^{-4} \mathrm{mg} / \mathrm{ml}$ of EoAa. Also in O. corniculata extracts, two cases of MIC and two cases of MBC equal to $10^{-4} \mathrm{mg} / \mathrm{ml}$ by AqOc extract were displayed.

Of the 51 isolates affected by the activity of $A$. annua products, 12 isolates were susceptible to EoAa only, and 5 isolates were susceptible to EoAa and EtAa extract alone, and 2 isolates were susceptible to EoAa and AqAa extract alone. Exclusive inhibitory effects of the A. annua products were detected on 11 isolates at the concentrations used, i.e. the bactericidal effects were not detected on them. EtAa extract MIC was lower than AqAa extract on 10 isolates, while AqAa extract efficacy was higher than EtAa extract on 13 isolates. EtOc extract showed no activity on 8 isolates out of 39 isolates susceptible to antimicrobial activity of $O$. corniculata extracts and MIC of AqOc extract was also lower on 19 isolates than EtOc extract.

3.3. Herbal Products and Antibiotics. The bacteriostatic effects of various concentrations of plant products were compared with particular concentration of antibiotics, the findings of which are showed in Figure 2. The results are based on the number of isolates which are inhibited by different plant products concentrations. The most potent product, i.e. EoAa with a $56.7 \%$ inhibition of all isolates, seems to have the potential to substitute 13 used antibiotics including oxacillin, amoxicillin, ampicillin, amoxicillin-clavulanic acid, tetracycline, streptomycin, ciprofloxacin, ceftriaxone, cefazolin, cefuroxime, cefotaxime, ceftazidime and cefixime $(P<$ $0.05)$. Other products in this concentration have a bacteriostatic range of $36.4 \%$ to $45.8 \%(P<0.05)$.

3.4. Phytcompounds Analysis. RP-HPLC and GC-MS were used to analyze the presence of polyphenols, including catechins, quercetin and chlorogenic acid, in the extracts of both plants, as well as the constituents of essential oil, respectively. In order to identify polyphenols and quantify their amounts in the extracts, their standards have been used that the standard chromatogram of these compounds was demonstrated in Figure 3. Catechins were detected in extracts from both plants, but the amount was higher in aqueous extracts than in ethanolic extracts (Figure 4). The levels of catechin in each 

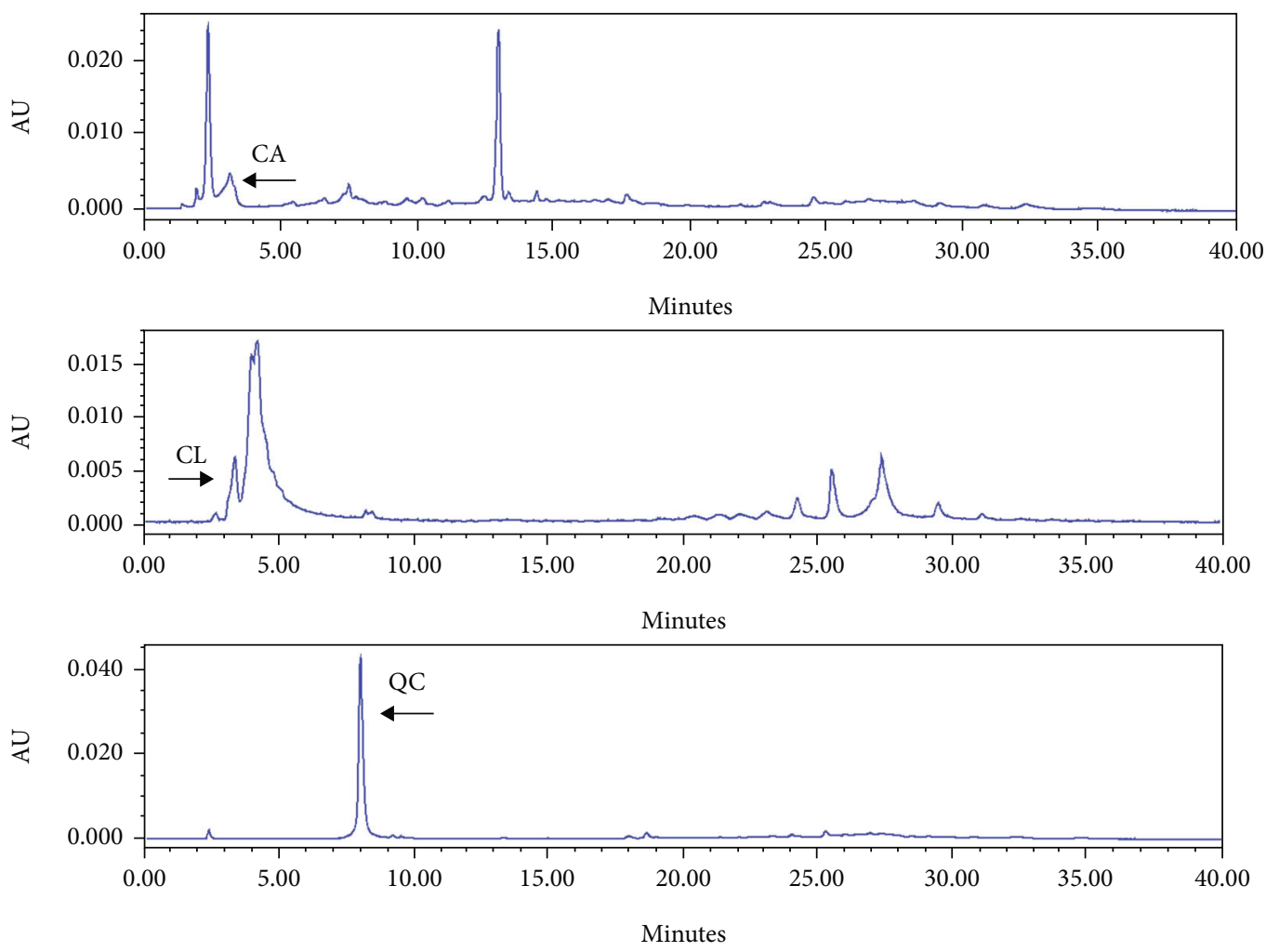

FIGURE 3: RP-HPLC chromatogram of the standards for catechin (CA, RT $=3.14 \mathrm{~min}$ ), chlorogenic acid $(\mathrm{CL}, \mathrm{RT}=4.2 \mathrm{~min})$ and quercetin $(\mathrm{QC}, \mathrm{RT}=8.00 \mathrm{~min}$ ) at 280,280 and $320 \mathrm{~nm}$, respectively.

of the products, including EtAa, AqAa, EtOc and AqOc extracts were $0.166,0.271,0.195$ and $0.348 \mathrm{~g} / 100 \mathrm{~g}$ DW, respectively. Quercetin was not detected in A. annua extracts and was higher in aqueous extract $(12.609 \mathrm{~g} / 100 \mathrm{~g} \mathrm{DW})$ than in EtOc extract ( $4.311 \mathrm{~g} / 100 \mathrm{~g}$ DW) (Figure 5). Chlorogenic acid could not be detected in extracts of both plants, except for the aqueous extract of $A$. annua $(0.684 \mathrm{~g} / 100 \mathrm{~g} \mathrm{DW})$ (Figure 4).

Phytochemical analysis of EoAa using GC-MS identified 31 peaks belonging to 7 types of compounds, including monoterpenes, sesquiterpenes, diterpene, cycloalkanes, cycloalkenes, alkyne and aldehyde (Table 4). Interestingly, about $50 \%$ of the EoAa constituents were terpenes, which included monoterpenes (16.25\%) (alpha-pinene, camphene, 1,8-cineole, terpineol, Z-beta, cis-sabinene hydrate, borneol, Myrtenol, trans-(+)-carveol, and verbenene) and sesquiterpenes $(21.8 \%)$ (alpha-copaene, rans-caryophyllene, germacrene, beta-selinene, bicyclogermacrene, caryophyllene oxide and ledene). The main terpenes contained germacrene (8.83\%), 1,8-cineole (5.98\%) and alpha-pinene (4.35\%).

\section{Discussion}

Despite significant progress in medicine, combating pathogenic microorganisms remains a major challenge due to their resistance to antibiotics. Aside from the emergence of antibiotic resistance, the side effects of antibiotics have prompted researchers to seek out new antimicrobials, particularly those derived from plants [42]. Although several studies, especially on A. annua, have been conducted due to their anti-malarial properties, the antimicrobial activity of $A$. annua and O. corniculata extracts was investigated in this study because of the importance and necessity of replacing antibiotics with plant products [21].

In the current study, two antimicrobial testing methods including agar well diffusion and microdilution, were used to assess antimicrobial activity. The results of the two antimicrobial tests were almost consistent. For several reasons, well diffusion method has limitations and is only used for initial screening. First, since essential oils and their constituents are hydrophobic, they do not disperse evenly in the agar medium [43]. Second, because the exact quantity of extract diffused into the agar medium is unknown, the well diffusion and disk diffusion methods provide qualitative rather than quantitative data [40].

The antimicrobial activity of the essential oil was higher than that of the extracts among the A. annua products. The explanation for this may be due to a greater variety of antibacterial compounds, the antimicrobial efficiency of essential oil materials, the type of plant cultivar, or the solvents used in the essential oil extraction, preparation, and so on [44]. The essential oil of this plant was the subject of the majority of antimicrobial studies performed on it [21-24]. The extracts of this plant had almost similar bacteriostatic and bacteriocide effects. This contradicted the findings of other research. Donato et al. studied the antimicrobial activity of $A$. annua essential oil and its major components against seven foodborne pathogens. The i.d of $1.27 \pm 0.31 \mathrm{~mm}$ and $\mathrm{MIC}=$ 

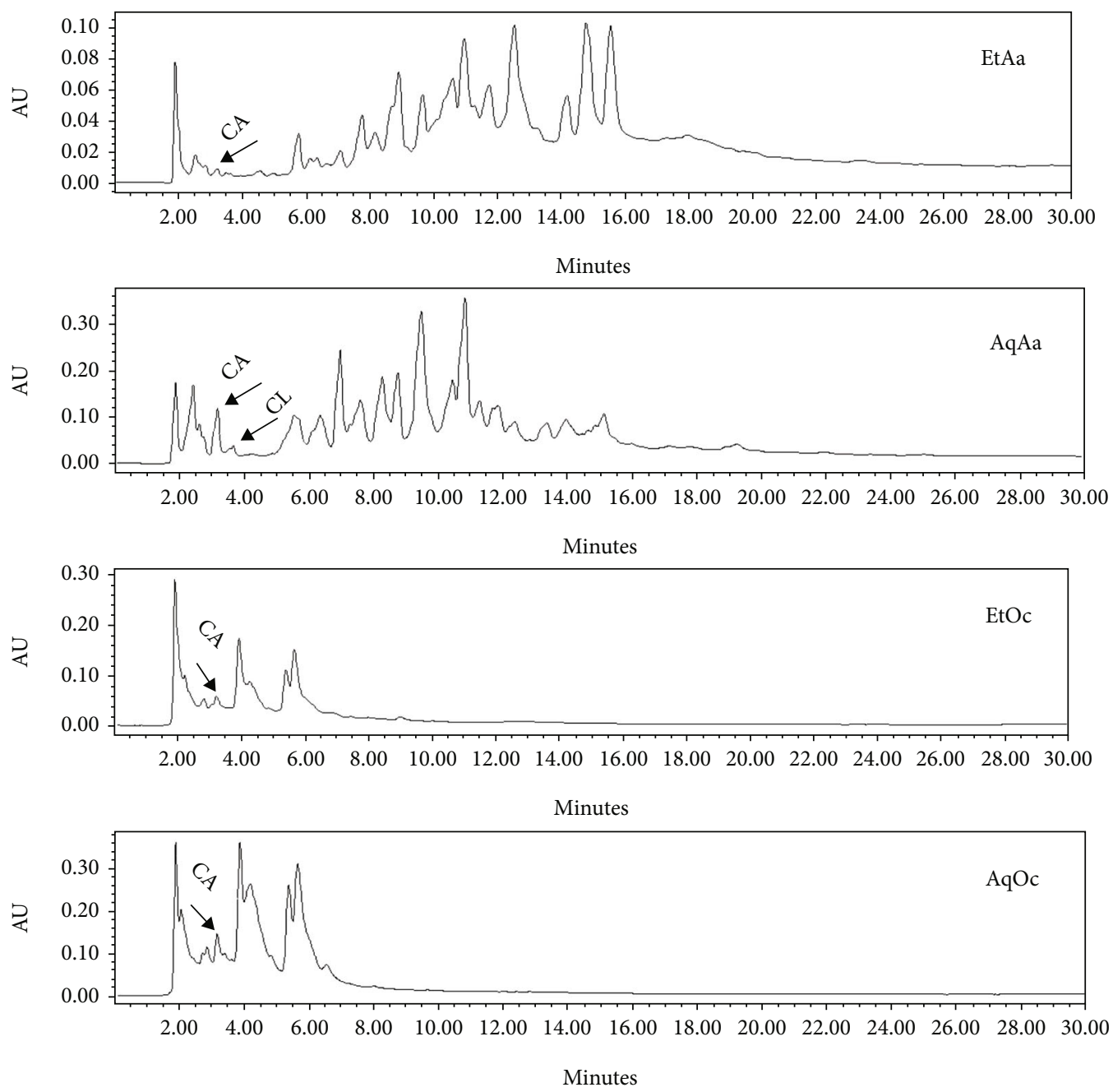

Figure 4: RP-HPLC chromatogram of catechin $(\mathrm{CA})$ in EtAa $(\mathrm{RT}=3.25 \mathrm{~min}), \mathrm{AqAa}(\mathrm{RT}=3.31 \mathrm{~min}), \mathrm{EtOc}(\mathrm{RT}=3.18 \mathrm{~min})$ and $\mathrm{AqOc}(\mathrm{RT}=$ $3.14 \mathrm{~min})$ extracts and chlorogenic acid $(\mathrm{CL})$ in AqAa $(\mathrm{RT}=3.79)$ extract detected at $280 \mathrm{~nm}$.
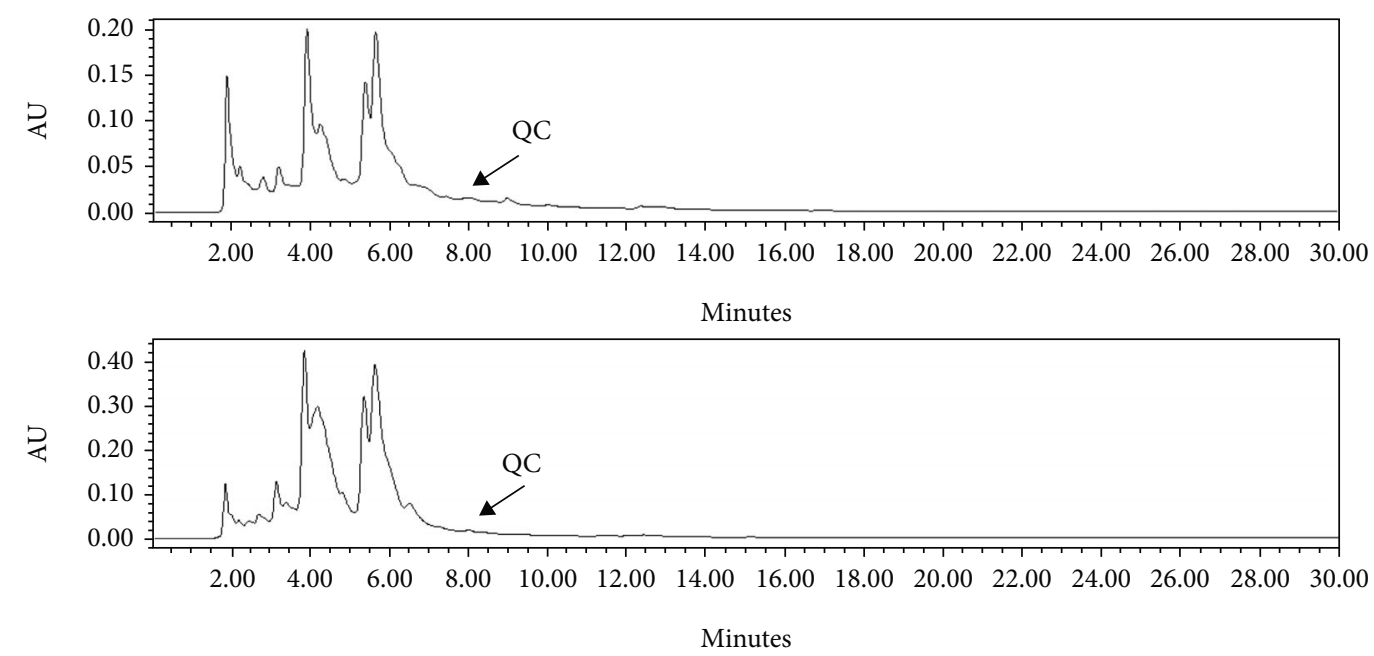

Figure 5: RP-HPLC chromatogram of quercetin in EtOc $(\mathrm{RT}=7.90)$ and AqOc $(\mathrm{RT}=7.97 \mathrm{~min})$ extracts detected at $320 \mathrm{~nm}$. This compound was not detectable in $A$. annua extracts. 
TABle 4: Phytoconstituents of EoAa detected by GC-MS analysis.

\begin{tabular}{|c|c|c|c|c|}
\hline Peak no. & Compound & $\mathrm{RT}$ & Area (\%) & Probability (\%) \\
\hline 1 & 2-Hexenal & 4.6 & 0.37 & 97 \\
\hline 2 & ALPHA.-PINENE & 6.77 & 4.35 & 96 \\
\hline 3 & Camphene & 7.23 & 0.74 & 98 \\
\hline 4 & Bicyclo[3.1.1]heptane, 6,6-dimethy 1-2-methylene & 8.12 & 0.57 & 97 \\
\hline 5 & 1,8 -cineole & 10.06 & 5.98 & 98 \\
\hline 6 & 1,5-Heptadien-4-one, 3,3,6-trimeth yl & 11.04 & 5.9 & 83 \\
\hline 7 & Terpineol, Z-.beta & 11.42 & 1.77 & 96 \\
\hline 8 & Cis-sabinene hydrate & 12.53 & 1.13 & 97 \\
\hline 9 & 2,3,3-Trimethyl-3-cyclopenteneace taldehyde & 13.38 & 1.16 & 86 \\
\hline 10 & Bicyclo[2.2.1]heptan-2-one, 1,7,7-trimethyl & 14.14 & 7.8 & 86 \\
\hline 11 & Bicyclo[2.2.1]heptan-2-one, 1,7,7- trimethyl & 14.25 & 6.84 & 97 \\
\hline 12 & Methyl-2-methylene- & 14.78 & 6.66 & 87 \\
\hline 13 & BORNEOL & 15.13 & 4.77 & 97 \\
\hline 14 & 3-Cyclohexen-1-ol, 4-methyl-1-(1-m ethylethyl)- & 15.38 & 2.07 & 98 \\
\hline 15 & Bicyclo[3.1.1]hept-2-ene-2-carboxa & 15.84 & 0.89 & 86 \\
\hline 16 & Myrtenol & 15.9 & 1.36 & 93 \\
\hline 17 & TRANS-(+)-CARVEOL & 16.68 & 0.52 & 98 \\
\hline 18 & Verbenene & 19.27 & 1.02 & 80 \\
\hline 19 & Alpha.-Copaene & 21.86 & 0.82 & 99 \\
\hline 20 & Trans-Caryophyllene & 23.3 & 3.59 & 99 \\
\hline 21 & 1,6,10-Dodecatriene, 7,11-dimethyl -3-methylene-, & 24.42 & 1.48 & 98 \\
\hline 22 & Germacrene & 25.31 & 8.83 & 98 \\
\hline 23 & Beta.-selinene & 25.53 & 4.06 & 99 \\
\hline 24 & Bicyclogermacrene & 25.65 & 0.69 & 97 \\
\hline 25 & Caryophyllene oxide & 28.21 & 0.58 & 91 \\
\hline 26 & Ledene & 29.53 & 1.64 & 92 \\
\hline 27 & Alpha.-Cubebene & 29.8 & 1.59 & 90 \\
\hline 28 & 7-Isopropenyl-4,4,10.Beta.-trimeth & 30.18 & 0.46 & 90 \\
\hline 29 & $\begin{array}{l}\text { 7-Isopropenyl-4,4,10.Beta--trimeth } \\
\text { Yl-1,2,3,4,7,8,9,10-octahydronapht halene }\end{array}$ & 32.1 & 1.46 & 90 \\
\hline 30 & 2,6-Diethenyl-4-tert-butylphenol & 32.35 & 0.86 & 78 \\
\hline 31 & Phytol & 41.8 & 1.3 & 91 \\
\hline 32 & & & 81.26 & \\
\hline
\end{tabular}

$17.6 \mathrm{mg} / \mathrm{ml}$ was obtained of these products against pathogens such as E. coli O157 [38]. The analysis of their essential oils revealed 27 compounds, of which monoterpenoids constituted $1.4 \%$ and cisquiterpenes constituted $91 \%$ of the essential oil, whereas in this study, monoterpenoids and cisquiterpenes constituted $16.25 \%$ and $21.8 \%$ of the 31 compounds found in the essential oils, respectively. However, some essential oil constituents were found to be identical in both studies.

In another report, Prakash et al. found that a methanolic extract of $A$. annua had higher antibacterial activity on Gram-positive and Gram-negative bacteria than other extracts, though this extract's antibacterial activity was not observed on Gram-negative bacteria including E. coli and Salmonella typhi, but it did show almost significant activity on Pseudomonas aeruginosa ( $\mathrm{MIC}=2 \mathrm{mg} / \mathrm{ml}$ and i.d = $17 \mathrm{~mm}$ ) [37]. In the Kim et al. survey, the resistance of peri- odontopathic bacteria to various extracts of $A$. annua varied, with only the aqueous extract having activity on Aggregatibacter actinomycetemcomitans ( $\mathrm{MIC}=14 \mathrm{mg} / \mathrm{ml}$ ) and this bacterium being resistant to other organic extracts [45]. The antimicrobial activity of different Artemisia species against pathogenic bacteria and fungi was found to be dependent on the solvent concentration used for extraction in the Hrytsyk et al. report [46]. Appalasamy et al. found that bioactive compounds isolated from A. annua, such as artemisinin and a precursor, had a poor inhibitory effect on Grampositive bacteria such as Bacillus subtilis, Staphylococcus aureus, and Bacillus thuringiensis, similar to streptomycin. As a result, using only one component of an essential oil might not be efficient, even though using, preparing, and applying each component is simpler and more appropriate than using essential oils or extracts. Their results show that MICs less than $0.09 \mathrm{mg} / \mathrm{ml}$ inhibit the growth of extract- 
susceptible microorganisms [47]. This MIC value was within the range of the MIC values obtained from research.

Rolta et al. examined the antimicrobial effects of methanolic and petroleum ether extracts of $A$. annua on drugresistant bacteria and fungi alone and in combination with antibiotics. Bacterial strains are more sensitive to Candida strains than to the bacteriostatic activity of these extracts, according to the results of their experiment. These extracts had a synergistic effect when combined with antibacterial and antifungal antibiotics, lowering MICs by 4-264 times against bacterial (S. aureus and E. coli) and Candida strains and increasing inhibitory activity. Using the diffusion method, none of these extracts showed antimicrobial activity against E. coli (ATCC25922) or S. aureus (ATCC29213), but methanolic extracts with $\mathrm{MIC}=0.125 \mathrm{mg} / \mathrm{ml}$ and ether extract with $\mathrm{MIC}=0.65 \mathrm{mg} / \mathrm{ml}$ inhibited both bacteria. In essential oil, thirteen compounds were identified, none of which were comparable to the essential oil compounds detected in this study [48].

According to the findings of Mamatova et al. ethanolic and chloroform extracts of Artemisia gmelinii may inhibit the growth of bacterial and Candida strains at $\mathrm{MIC}=1.5$ $20 \mathrm{mg} / \mathrm{ml}$. The extracts had the greatest bacteriostatic effect on yeasts, Gram-positive bacteria, and Gram-negative bacteria, respectively [40].

Hameed et al. evaluated the antimicrobial activity of $A$. annua methanolic extracts on E. coli and S. aureus. Both isolates had an i.d range of $0.70 \pm 0.10$ to $50 \pm 0.20 \mathrm{~mm}$, with $E$. coli having an i.d of $3.17 \pm 0.15 \mathrm{~mm}$, which was less than the minimum i.d ( $40.33 \mathrm{~mm}$ ) obtained in this study. Antibiotics such as cefuroxime, streptomycin, and rifampin had a lower inhibitory effect on $E$. coli than methanolic extract, even though the inhibitory effect of the extracts used in this study was lower than streptomycin and cefuroxime. Phytochemical analysis of essential oils identified 59 compounds that were almost entirely different from the compounds found in the current research [49].

In the current survey, the extracts were assayed for antibacterial flavonoid compounds including catechins, quercetin and chlorogenic acid. Catechin appears to be working through many different mechanisms. It disrupts cell membranes by binding to bilayer membranes and inhibiting or inactivating the synthesis of intracellular and extracellular enzymes [50], as well as respiratory bursts by generating reactive oxygen intermediates (ROIs) [51], which disturb membrane permeability. Catechin also disrupts cell wall synthesis by binding to peptidoglycans [52]. Several antibacterial mechanisms, including DNA gyrase inhibition [53], ATP hydrolysis inhibition [54], and metal complexation [55], have been proposed for quercetin. Chlorogenic acid, like catechin, damages cell membranes [56].

Using liquid chromatography/diode array detectoratmospheric pressure chemical ionization/mass spectrometry (LC/DAD-APCI/MS) at $335 \mathrm{~nm}$, Lai et al. and Han et al. were able to detect more than 40 compounds in the methanolic extract of $A$. annua, including chlorogenic acid and quercetin, while only chlorogenic acid was detected in the aqueous extract in the current study $[57,58]$. Ivanescu et al. qualitatively detected chlorogenic acid in the methanolic extract of the aerial portion of A. annua and, in contrast to our research, was able to identify and quantify quercetin at $2.456 \mathrm{mg} / 100 \mathrm{~g}$ dry herb and $3.33 .6 \mathrm{mg} / 100 \mathrm{~g}$ dry herb in the methanolic extract alone and treated with hydrochloric acid, respectively [59]. In the Carvalhoa et al. analysis, catechins, quercetin, and chlorogenic acid were detected in the methanolic extract of $A$. annua leaves in amounts of $79.53 \pm 0.123,0.74 \pm 0.004$, and $0.76 \pm 0.022 \mathrm{mg} / \mathrm{g}$ dry matter, respectively. Catechin levels were approximately 35 times higher than those measured in AqAa extract (the highest amount of catechin and the only product containing chlorogenic acid) of our sample, but chlorogenic acid levels were about 9 times lower [60].

In this research, among $O$. corniculata products, aqueous extract had a higher antimicrobial potency than ethanolic extract. Adnan Siddiqui et al. reported that different O. corniculata extracts had different effects on Gram-positive and Gram-negative bacteria. According to their results, the most active extracts were aqueous and methanol extracts, which were comparable to tetracycline inhibition activity. Phytochemical analysis of extracts with the highest inhibitory activity indicated the existence of antimicrobial compounds such as phenolic compounds, alkaloids, flavonoids, and others [61]. In another study conducted by the Mukherjee et al. the bacteriostatic activity of methanolic extract of $O$. corniculata leaf was observed against pathogenic bacteria such as E. coli, Shigella spp. and S. aureus, so that the i.d ranged from $12 \pm 0$ to $19 \pm 0.5 \mathrm{~mm}$ and the highest was correlated with E. coli. The MIC range was $0.08 \pm 0.00$ to $0.13 \pm$ $0.00 \mathrm{mg} / \mathrm{ml}$, with the lowest $0.08 \pm 0.00 \mathrm{mg} / \mathrm{ml}$ against $E$. coli. In comparing extracts and antibiotics against $E$. coli, the extract had a higher bacteriostatic rate than the antibiotics ampicillin, doxycycline, and streptomycin, but the MIC value was different from the diameter determination, and the amount of MIC of ampicillin and streptomycin is half that of the extract against E. coli [62].

In a study conducted by Manandhar et al. that evaluated methanolic extracts from various Oxalis species against pathogenic bacteria, as well as Aspergillus and Rhizopus spp., only $O$. corniculata extract was effective against $E$. coli, while other bacteria, such as $P$. aeruginosa and S. aureus, as well as fungi, were not susceptible to this extract. In their analysis, the results of agar well diffusion and microdilution tests were not consistent [63]. In a study by Das et al. the antibacterial activity of $O$. corniculata aqueous extract as biofabricated silver nanoparticles (AgNPs) against UTI-causing bacteria was many times higher than normal extract [64]. Rahman et al. found that methanolic extract had more bacteriostatic activity against Gram-positive and Gram-negative bacteria than ethanolic extract, but the bacteriostatic activity of both extracts was lower than that of the cephachlore antibiotic [65]. In a different experiment, the antibacterial activity of $O$. corniculata leaf methanolic extract was reported to be greater than that of other organic extracts, as well as erythromycin and nalidixic acid, against a variety of bacteria, resulting in the highest rate of inhibition against S. aureus [66]. In a study that was almost similar to the previous two, the more potent activity of $O$. corniculata methanolic extract was reported in most cases, while chloroform, petroleum ether, 
and benzene extracts had no effect on at least eight human pathogenic bacteria. Interestingly, the effect of ethanolic extract on E. coli was greater than that of methanolic extract alone, and the sensitivity of bacteria to two antibiotics was higher than that of both extracts when compared to gentamicin and streptomacin. According to phytochemical analysis, the contents of compounds such as phenolic compounds and flavonoids are higher in methanolic and ethanolic extracts [28].

In analysis of phytochemical components and antibacterial potential of different parts of $O$. corniculata against $P$. aeruginosa and Rhodococcus fascians by Kaur et al., it was found that the leaves had more flavonoid and phenolic contents, and the seeds and stems had less phenolic and flavonoid contents, respectively. Leaves and seeds had the highest and lowest antibacterial activity, respectively [67]. Phytochemical assay of $O$. corniculata leaves grown in moist, marshy and dry areas revealed that 13 phenolic compounds, including quercetin $(0.226 \mu \mathrm{g} / \mathrm{g})$, are more abundant in dry samples, followed by marshy and moist samples. However, the total flavonoid and phenolic content of the samples differed [68].

In most cases, the antimicrobial potency of the herbal products used in this research differed from that of other studies. Despite the fact that methanolic extract was not used in this study, results from other studies have shown that it is the most effective extract. Methanol is probably to be a suitable correlation with phenolic compounds, thus increasing its antimicrobial activities. The essential oils used in this analysis had different components and activities than those used in other studies, but some of the components were similar. However, the proportions of the components were different. This can be affected by method of extraction, distillation equipment, soil physicochemical parameters, plant age, plant cultivation techniques, density of plant population, harvest time, branch and leaf condition, relative humidity, the geographic environment, climate and managers [44].

\section{Conclusion}

The findings of the present study showed that the studied herbal products had almost significant antibacterial activity on MDR E. coli isolates, but in order to select a more appropriate and effective medication from these plants that can be used as an alternative to antibiotics, food preservative and as a candidate for treatment of UTIs, consideration should be given to methods and use of other solvents for extraction as well as further pharmaceutical analysis.

\section{Data Availability}

All data used during the study are available from the corresponding author by request.

\section{Conflicts of Interest}

The authors declare that they have no conflict of interest.

\section{Authors' Contributions}

This work was taken from the thesis of HG. The idea, data analysis and conduction of this research were made by MJMM, while the experimental steps were performed by HG. This paper has been interpreted and written by MJMM.

\section{Acknowledgments}

The author sincerely thanks the faculty of sciences, University of Guilan, for providing laboratory facilities.

\section{References}

[1] L. M. Weiner-Lastinger, S. Abner, J. R. Edwards et al., "Antimicrobial-resistant pathogens associated with adult healthcare-associated infections: summary of data reported to the National Healthcare Safety Network, 2015-2017," Infection Control and Hospital Epidemiology, vol. 41, no. 1, pp. 118, 2020.

[2] S. Sabir, A. A. Anjum, T. Ijaz, M. A. Ali, M. U. Rehman, and M. Nawaz, "Isolation and antibiotic susceptibility of E. coli from urinary tract infections in a tertiary care hospital," Pakistan Journal of Medical Sciences, vol. 30, no. 2, p. 389, 2014.

[3] J. A. Otter, T. J. Galletly, F. Davies et al., "Planning to halve gram-negative bloodstream infection: getting to grips with healthcare-associated Escherichia coli bloodstream infection sources," Journal of Hospital Infection, vol. 101, no. 2, pp. 129-133, 2019.

[4] M. M. Cowan, "Plant products as antimicrobial agents," Clinical Microbiology Reviews, vol. 12, no. 4, pp. 564-582, 1999.

[5] B. H. Oladeinde, R. Omoregie, and O. B. Oladeinde, "Asymptomatic urinary tract infection among pregnant women receiving ante-natal care in a traditional birth home in Benin City, Nigeria," Ethiopian Journal of Health Sciences, vol. 21, no. 1, pp. 3-8, 2015.

[6] Y. R. Nairoukh, A. M. Mahafzah, A. Irshaid, and A. A. Shehabi, "Molecular characterization of multidrug resistant uropathogenic E. coli isolates from Jordanian patients," Open Microbiology Journal, vol. 12, pp. 1-7, 2018.

[7] D. Styers, D. J. Sheehan, P. Hogan, and D. F. Sahm, "Laboratory-based surveillance of current antimicrobial resistance patterns and trends among Staphylococcus aureus: 2005 status in the United States," Annals of Clinical Microbiology and Antimicrobials, vol. 5, p. 2, 2006.

[8] R. P. Borris, "Natural products research: perspectives from a major pharmaceutical company," Journal of Ethnopharmacology, vol. 51, no. 1-3, pp. 29-38, 1996.

[9] J. Zheng, C. Huang, B. Yang, H. Kallio, P. Liu, and S. Ou, "Regulation of phytochemicals in fruits and berries by environmental variation-sugars and organic acids," Journal of Food Biochemistry, vol. 43, article e12642, 2019.

[10] A. Mate, Medicinal and Aromatic Plants of the World. Scientific, Production, Commercial and Utilization Aspects, Springer Science + Business Media, 2015.

[11] H. Chandra, P. Bishnoi, A. Yadav, B. Patni, A. Mishra, and A. Nautiyal, "Antimicrobial Resistance and the Alternative Resources with Special Emphasis on Plant-Based Antimicrobials-A Review," Plants, vol. 6, no. 2, p. 16, 2017. 
[12] A. M. Mileo, P. Nisticò, and S. Miccadei, "Polyphenols: immunomodulatory and therapeutic implication in colorectal cancer," Frontiers in Immunology, vol. 10, p. 729, 2019.

[13] A. K. Singh, C. Cabral, R. Kumar et al., "Beneficial effects of dietary polyphenols on gut microbiota and strategies to improve delivery efficiency," Nutrients, vol. 11, no. 9, article 2216, 2019.

[14] S. Quideau, D. Deffieux, C. D. Casassus, and L. Pouységu, "Plant polyphenols: chemical properties, biological activities, and synthesis," Angewandte Chemie International Edition, vol. 50, no. 3, pp. 586-621, 2011.

[15] L. Vlase, D. Benedec, D. Hanganu et al., "Evaluation of antioxidant and antimicrobial activities and phenolic profile for $\mathrm{Hys}$ sopus officinalis, Ocimum basilicum and Teucrium chamaedrys," Molecules, vol. 19, no. 5, pp. 5490-5507, 2014.

[16] K. Morteza-Semnani, M. Akbarzadeh, and K. Moshiri, "Essential oil composition of Artemisia fragrans willd. from Iran," Flavour and Fragrance Journal, vol. 20, pp. 330-331, 2005.

[17] V. Mozaffarian, A Dictionary of Iranian Plant Names, Farhang Moaser, 1996.

[18] A. R. Bilia, F. Santomauro, C. Sacco, M. C. Bergonzi, and R. Donato, "Essential oil of Artemisia annua L.: An extraordinary component with numerous antimicrobial properties," Evidence-Based Complementary and Alternative Medicine, vol. 2014, Article ID 159819, 7 pages, 2014.

[19] S. Cavar, M. Maksimović, D. Vidić, and A. Parić, "Chemical composition and antioxidant and antimicrobial activity of essential oil of Artemisia annua L., from Bosnia," Industrial Crops and Products, vol. 37, no. 1, pp. 479-485, 2012.

[20] I. Dib, L. Angenot, A. Mihamou, A. Ziyyat, and M. Tits, "Artemisia campestris L.: Ethnomedicinal, phytochemical and pharmacological review," Journal of Herbal Medicine, vol. 158, no. 10, pp. 1-10, 2017.

[21] L. Das, S. Czuni, V. Báló et al., "Cytotoxic action of artemisinin and scopoletin on planktonic forms and on biofilms of Candida species," Molecules, vol. 25, no. 3, p. 476, 2020.

[22] A. M. Galal, S. A. Ross, M. Jacob, and M. A. ElSohly, "Antifungal activity of artemisinin derivatives," Journal of Natural Products, vol. 68, no. 8, pp. 1274-1276, 2005.

[23] T. Efferth, "From ancient herb to modern drug: Artemisia annua and artemisinin for cancer therapy," Seminars in Cancer Biology, vol. 46, pp. 65-83, 2017.

[24] G. J. B. Gnonlonfin, A. Sanni, and L. Brimer, "Review scopoletin - a coumarin phytoalexin with medicinal properties," Critical Reviews in Plant Sciences, vol. 31, no. 1, pp. 47-56, 2012.

[25] S. K. Bhattacharjee, Handbook of Medicinal Plants, Pointer Publishers, 1998.

[26] F. Ghahremaninejad and F. Gholamian, "A new record (Oxalis articulata) from Iran - Iran," Journal of Botany, vol. 12, 56 pages, 2006.

[27] M. Pallab, H. Dhananjay, B. Uday, and D. K. Mishra, "Biological activities of crude extracts and chemical constituents of Aegle marmelos (L.) Corr.," Indian Journal of Experimental Biology, vol. 47, no. 11, pp. 849-861, 2009.

[28] M. P. Raghvendra, S. Satish, and K. A. Raveesha, "Phytochemical analysis and antibacterial activity of Oxalis corniculata, a known medicinal plant," MyScience, vol. 1, no. 1, pp. 72-78, 2006.

[29] B. G. Unni, B. Archana, S. B. Wann, H. R. Singh, B. Devi, and M. Bhattacharjee, "Phytochemical and antibacterial study of traditional medicinal plants of north East India on Escherichia coli," Asian Journal of Experimental Sciences, vol. 23, no. 1, pp. 103-108, 2009.

[30] C. R. Kiffer, C. Mendes, and C. P. Oplustil, "Antibiotic resistance and trend of urinary pathogens in general outpatients from a major urban city," International Brazilian Journal of Urology, vol. 33, no. 1, pp. 42-49, 2007.

[31] K. Al Benwan, N. Al Sweih, and V. O. Rotimi, "Etiology and antibiotic susceptibility patterns of community-and hospitalacquired urinary tract infections in a general hospital in Kuwait," Medical Principles and Practice, vol. 19, no. 6, pp. 440-446, 2010.

[32] J. A. Washington, Laboratory Procedures in Clinical Microbiology, Springer Science \& Business Media, 2012.

[33] M. Balouiri, M. Sadiki, and S. K. Ibnsouda, "Methods for in vitro evaluating antimicrobial activity: a review," Journal of Pharmaceutical Analysis, vol. 6, no. 2, pp. 71-79, 2016.

[34] CLSI, Performance standards for antimicrobial disk susceptibility tests, approved standard, CLSI document M02-A11, Clinical and Laboratory Standards Institute, 7th edition, 2012.

[35] E. Panda, C. Pradhan, and A. B. Das, "Variations in phytoconstituents and antimicrobial activities in ecotypes of Oxalis corniculata L. and Oxalis debilis Kunth," International Journal of Pharmacy and Pharmaceutical Sciences, vol. 8, no. 10, pp. 270275, 2016.

[36] K. Haile Asressu and T. Kebede Tesema, "Chemical and antimicrobial investigations on essential oil of Rosmarinus officinalis leaves grown in Ethiopia and comparison with other countries," Journal of Applied Pharmacy, vol. 6, no. 2, pp. 132-142, 2014.

[37] C. Prakash, B. Gupta, P. Joshi, and D. R. Lohar, "In vitro antibacterial activity of Artemisia annua L., growing in India," International Journal of Green Pharmacy, vol. 3, no. 3, pp. 255-258, 2009.

[38] R. Donato, F. Santomauroa, and A. Rita Bilia, "Antibacterial activity of Tuscan Artemisia annua essential oil and its major components against some foodborne pathogens," Food Science and Technology, vol. 64, no. 2, pp. 1251-1254, 2015.

[39] G. L. French, "Bactericidal agents in the treatment of MRSA infections - the potential role of daptomycin," Journal of Antimicrobial Chemotherapy, vol. 58, no. 6, pp. 11071117, 2006.

[40] A. S. Mamatova, I. Korona-Glowniak, K. Skalicka-Woźniak et al., "Phytochemical composition of wormwood (Artemisia gmelinii) extracts in respect of their antimicrobial activity," BMC Complementary and Alternative Medicine, vol. 19, p. 288, 2019.

[41] G. Flamini, A. Bader, P. Luigi Cioni, A. Katbeh-Bader, and I. Morelli, "Composition of the essential oil of leaves, galls, and ripe and unripe fruits of ordanian Pistacia palaestina Boiss," Journal of Agricultural and Food Chemistry, vol. 52, no. 3, pp. 572-576, 2004.

[42] R. Subramani, M. Narayanasamy, and K. D. Feussner, "Plantderived antimicrobials to fight against multi-drug-resistant human pathogens," 3 Biotech, vol. 7, no. 3, p. 172, 2017.

[43] S. Cavar, M. Maksimovi, D. Vidic, and A. Parić, "Chemical composition and antioxidant and antimicrobial activity of essential oil of Artemisia annua L. from Bosnia," Industrial Crops and Products, vol. 37, no. 1, pp. 479-485, 2012.

[44] D. Zewdineh, T. Bizuayehu, and B. Daniel, "Leaf essential oil and artemisinin yield of Artemisia (Artemisia annua L.) as influenced by harvesting age and plant population density," 
World Journal of Agriculture and Soil Science, vol. 7, no. 4, pp. 404-412, 2011.

[45] W. S. Kim, W. J. Choi, and S. Lee, “Anti-inflammatory, antioxidant and antimicrobial effects of artemisinin extracts from Artemisia annua L.," Korean Journal of Physiology and Pharmacology, vol. 19, no. 1, pp. 21-27, 2015.

[46] R. A. Hrytsyk, R. V. Kutsyk, and O. I. Yurchyshyn, "The investigation of antimicrobial and antifungal activity of some Artemisia L. species,” Pharmacia, vol. 68, no. 1, pp. 93-100, 2011.

[47] S. Appalasamy, K. Y. Lo, S. J. Ch'ng, K. Nornadia, A. S. Othman, and L.-K. Chan, "Antimicrobial activity of artemisinin and precursor derived from in vitro plantlets of Artemisia aпnua L.," BioMed Research International, vol. 2014, Article ID 215872, 6 pages, 2014.

[48] R. Rolta, A. Sharma, A. Sourirajan, P. K. Mallikarjunan, and K. Dev, "Combination between antibacterial and antifungal antibiotics with phytocompounds of Artemisia annua L: a strategy to control drug resistance pathogens," Journal of Ethnopharmacology, vol. 266, article 113420, 2021.

[49] I. H. Hameed, H. Jasim Altameme, and S. Ali Idan, "Artemisia annua: biochemical products analysis of methanolic aerial parts extract and anti-microbial capacity," Research Journal of Pharmaceutical, Biological and Chemical Sciences, vol. 7, no. 2, pp. 1843-1868, 2016.

[50] W. C. Reygaert, "The antimicrobial possibilities of green tea," Frontiers in Microbiology, vol. 5, p. 434, 2014.

[51] A. Fathima and J. R. Rao, "Selective toxicity of Catechin-a natural flavonoid towards bacteria," Applied Microbiology and Biotechnology, vol. 100, no. 14, pp. 6395-6402, 2016.

[52] W. H. Zhao, Z. Q. Hu, S. Okubo, Y. Hara, and T. Shimamura, "Mechanism of synergy between epigallocatechin gallate and $\beta$-lactams against methicillin-resistant Staphylococcus aureus," Antimicrobial Agents and Chemotherapy, vol. 45, no. 6, pp. 1737-1742, 2001.

[53] K. A. Ohemeng, C. F. Schwender, K. P. Fu, and J. F. Barrett, "DNA gyrase inhibitory and antibacterial activity of some flavones," Bioorganic and Medicinal Chemistry Letters, vol. 3, no. 2, pp. 225-230, 1993.

[54] N. Chinnam, P. K. Dadi, S. A. Sabri, M. Ahmad, M. A. Kabir, and Z. Ahmad, "Dietary bioflavonoids inhibit Escherichia coli ATP synthase in a differential manner," International Journal of Biological Macromolecules, vol. 46, no. 5, pp. 478-486, 2010.

[55] A. Bravo and J. R. Anacona, "Metal complexes of the flavonoid quercetin: antibacterial properties," Transition Metal Chemistry, vol. 26, pp. 20-23, 2001.

[56] Z. Lou, H. Wang, S. Zhu, C. Ma, and Z. Wang, “Antibacterial activity and mechanism of action of chlorogenic acid," Journal of Food Science, vol. 76, no. 6, pp. 398-403, 2011.

[57] J. P. Lai, Y. H. Lim, J. Su, H.-M. Shen, and C. N. Ong, "Identification and characterization of major flavonoids and caffeoylquinic acids in three Compositae plants by LC/DADAPCI/MS," Journal of Chromatography, vol. 484, no. 2, pp. 215-225, 2007.

[58] J. Han, M. Ye, X. Qiao, M. Xu, B. R. Wang, and D.-A. Guo, "Characterization of phenolic compounds in the Chinese herbal drug Artemisia annua by liquid chromatography coupled to electrospray ionization mass spectrometry," Journal of Pharmaceutical and Biomedical Analysis, vol. 47, no. 3, pp. 516-525, 2008.

[59] B. Ivanescu, L. Vlase, A. Corciova, and M. I. Lazar, "HPLCDAD-MS study of polyphenols from Artemisia absinthium,
A. annua, and A. vulgaris," Chemistry of Natural Compounds, vol. 46, pp. 468-470, 2010.

[60] I. S. Carvalhoa, T. Cavacoa, and M. Brodelius, "Phenolic composition and antioxidant capacity of six artemisia species," Industrial Crops and Products, vol. 33, no. 2, pp. 382-388, 2011.

[61] M. Adnan Siddiqui, R. Kant Singh, and A. Kumar, "Phytochemical screening and antibacterial activity of Oxalis corniculata against human pathogens," International Journal of Current Research, vol. 9, no. 12, pp. 62114-62118, 2017.

[62] S. Mukherjee, H. Koley, S. Barman et al., "Oxalis corniculata (Oxalidaceae) leaf extract exerts in vitro antimicrobial and in vivo anticolonizing activities against Shigella dysenteriae 1 (NT4907) and Shigella flexneri 2a (2457T) in induced diarrhea in suckling mice," Journal of Medicinal Food, vol. 16, no. 9, pp. 801-809, 2013.

[63] S. Manandhar, S. Luitel, and R. Kumar Dahal, "In vitro antimicrobial activity of some medicinal plants against human pathogenic bacteria," Journal of Tropical Medicine, vol. 2019, Article ID 1895340, 5 pages, 2019.

[64] P. Das, K. Kumar, A. Nambiraj, R. Awasthi, K. Dua, and H. Malipeddi, "Antibacterial and in vitro growth inhibition study of struvite urinary stones using Oxalis corniculata Linn. Leaf extract and its biofabricated silver nanoparticles," Recent Patents on Drug Delivery \& Formulation, vol. 12, no. 3, pp. 170-178, 2018.

[65] M. Rahman, R. Shahriar, N. Sultana Meghla, T. Ishika, P. C. Roy, and M. Kamruzzaman, "Antimicrobial activity of some medicinal plant extracts against gram positive and gram negative bacteria in Bangladesh," Asian Journal of Medical and Biological Research, vol. 3, no. 4, pp. 405-411, 2017.

[66] S. Rahman, M. M. H. Khan, and M. Jamal, “Antibacterial evaluation and minimum inhibitory concentration analysis of Oxalis corniculata and Ocimum santum against bacterial pathogens," Biotechnology, vol. 9, no. 4, pp. 533-536, 2010.

[67] S. Kaur, G. Kaur, and J. Singh, "Phytochemical screening and biological potential of methanolic extract of Oxalis corniculata using different parts of plant," Research Journal of Chemical, vol. 7, no. 7, pp. 26-32, 2017.

[68] A. Zeb and M. Imran, "Carotenoids, pigments, phenolic composition and antioxidant activity of Oxalis corniculata leaves," Food Bioscience, vol. 32, article 100472, 2019. 